\title{
Relationship between Otolaryngologic Complaints and Systemic Comorbidities Observed in a Group of Hearing Aid Users
}

\author{
Angela Ribas ${ }^{1}$ Renata Silvestre $^{1} \quad$ Carla Meller Mottecy $^{1} \quad$ Lorena Kozlowski $^{2} \quad$ Jair Mendes Marques $^{1}$ \\ ${ }^{1}$ Communication Disorders Postgraduate Program, Universidade \\ Tuiuti do Paraná, Curitiba, Paraná, Brazil \\ 2 Department of Audiology, Centro de Audição e Linguagem, Curitiba, \\ Paraná, Brazil

\begin{abstract}
Address for correspondence Angela Ribas, Communication Disorders Postgraduate Program, Universdidade Tuiuti do Paraná, Universidade Tuiuti do Paraná, Rua Jose Isidoro Biazetto 845, Curitiba, PR 81200240 ,
\end{abstract} \\ Brazil (e-mail: angela.ribas@utp.br).
}

\begin{abstract}
Introduction Optimization of the selection, adaptation, and benefit of hearing aids is necessary to characterize and manage hearing loss, user expectations, otolaryngologic symptoms, and systemic comorbidities.

Objective To compare the occurrence of otologic complaints, systemic diseases, and effective use of hearing aids in men and women with deafness.

Methods Patients from a Unified Health System-accredited hearing health service, who reported problems in adapting to their hearing aids, were evaluated by a physician and audiologist. An anamnesis, ENT evaluation, and audiological evaluation were performed.

Results During the data collection period, 278 subjects came in for follow-up visits; of these, $61(21 \%)$ reported otologic or operational problems with their equipment. The most prevalent type of hearing loss was basocochlear, a characteristic of presbycusis, in both men and women; the most frequently reported comorbidities were hypercholesterolemia (more significant in women) and hypertension (more significant in men). Fourteen subjects reported using their device discontinuously, with no significant

Keywords

- hearing loss

- protocols

- hearing aids

- ear diseases

- chronic disease difference between genders; the reasons for discontinuation of use were itching and ringing, with more complaints from women.

Conclusion The incidence of systemic and audiological complaints is high in this population. These patients should be evaluated thoroughly, as resolutions of these complaints can contribute to improving the quality of life and assist in the process of hearing aid fitting.
\end{abstract}

\section{Introduction}

Although some recent studies have shown declines in the prevalence of hearing impairment in recent generations, ${ }^{1,2}$ according to World Health Organization global estimates, it still represents the most common sensory disorder in the world, with 328 million adults having disabling hearing loss (hearing thresholds above $40 \mathrm{~dB}$ ), which can impair their quality of life

received

May 12, 2014

accepted after revision

October 18, 2014

published online

November 28, 2014

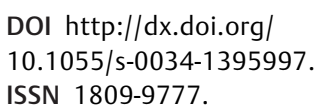

and potentially result in feelings of isolation, loneliness, and frustration due to communication difficulties, economic participation, and lack of access to services. ${ }^{3,4}$ However, even in developed countries, it is estimated that less than 1 in 40 people who need hearing aids have access to them. ${ }^{3}$

In 2004, with the establishment of the National Hearing Health Care Policy, the Brazilian government, through the
Copyright $\odot 2015$ by Thieme Publicações License terms Ltda, Rio de Janeiro, Brazil

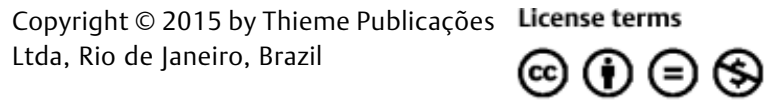


Unified Health System (SUS), via the Organization of State Hearing Health Networks, made it possible for the population to have access to the service levels of basic, medium, and highcomplexity audiological care. ${ }^{5}$

In parallel, the processes of globalization and urbanization have resulted in changes in lifestyle. Inactivity and unhealthy diet have resulted in an epidemic of excess weight, ${ }^{6}$ associated with stress, smoking, and alcohol abuse. In turn, these conditions have led to an increased prevalence of chronic diseases, the most common being cardiovascular, which includes hypertension and hypercholesterolemia; osteoarticular; psychiatric disorders; chronic respiratory diseases; diabetes; kidney disease; and cancer. ${ }^{6-9}$ All are significantly more prevalent in women. ${ }^{10}$ Certain chronic degenerative diseases may contribute to the onset and worsening of hearing loss via different pathophysiological mechanisms. ${ }^{7,8}$

According to the National Sampling Policy of Households (PNAD), conducted by the Brazilian Institute of Geography and Statistics in 2008, hypertension is the most prevalent chronic disease in both sexes. ${ }^{10-12}$ It evolves from increased blood viscosity and microcirculatory failure that can compromise the auditory and vestibular systems at the peripheral and central levels. This is aggravated by hypercholesterolemia, which affects one-third of individuals over 45 years of age. $6,7,13$

Diabetes, although the seventh most prevalent chronic disease in the same PNAD statistics, showed the strongest growth, up $37 \%$, compared with the prevalence described in the 2003 study. ${ }^{6,9}$ Although there is still no consensus on the pathophysiology of hearing damage caused by diabetes, it is suggested that changes in the metabolism of lipids and glucides could be related to the development and/or aggravation of not only hearing loss but also tinnitus and balance disorders because of reduced blood flow and disability in the transport of nutrients, due to diabetic microangiopathy and secondary degenerative neuropathy affecting peripheral and central auditory pathways. ${ }^{7,14,15}$

Such situations, besides contributing to the concomitant hypoacusis with other otologic complaints, ${ }^{16-18}$ increase the progression of hearing loss and are of the utmost importance when selecting and fitting hearing aids.

Several studies have shown the high concurrency of otologic symptoms in hearing aid users, especially tinnitus, dizziness, itching, and ear pain. Although results vary, tinnitus symptoms have been reported by at least $70 \%$ of the subjects in most polls, followed by itching and/or dizziness in $\sim 50 \%$ of individuals. ${ }^{19-21}$ Tenório et al found that $100 \%$ of a sample for hearing aid wearers had at least one associated symptom. $^{12}$

If on the one hand adaptation of the hearing aids has improved some of these symptoms, ${ }^{20-23}$ then on the other hand, hearing aid user may be related to a worsening clinical picture in cases of allergic contact dermatitis ${ }^{24,25}$ and even worse tinnitus if the device has no ventilation or is an open mold. $^{22}$

Such symptoms can compromise the benefits of hearing aid use. Recently, Andersson et al found that hearing aid users with tinnitus had worse responses than the group without tinnitus in unfavorable listening situations (low signal-tonoise ratio), generating more complaints than improvements with the device. ${ }^{26}$

The impact of hearing loss in the world, the prevalence of systemic diseases and otologic symptoms in the adult population, in addition to the increase in number of SUS users getting hearing aids show the importance of developing protocols for integrated assessment of candidates for fitting. Greater attention should be paid to device selection and adaptation to better characterize and manage hearing loss and user expectations and otolaryngologic symptoms associated with systemic comorbidities to optimize the hearing aid fitting process.

This study aims to compare the occurrence of otologic complaints, systemic diseases, and effective use of hearing aids in men and women with deafness.

\section{Methods}

This is an exploratory, descriptive, cross-sectional study, approved by the Research Ethics Committee under the number CEP/027/2008. All participants signed a consent form authorizing the use of the collected data.

Between March and September 2013, during the development of this research, 278 patients using hearing aids were followed by the otolaryngology service at a hearing health service center accredited by SUS in Curitiba, Brazil. For this study, individuals were selected who fit the following criteria: over 50 years old with a diagnosis of hearing loss, hearing aid use for at least the past 6 months, having complaints about the adaptation and/or functioning of the device. Following this criteria the sample was composed of 61 respondents.

All subjects were evaluated by an ear, nose, and throat (ENT) physician and audiologist. An anamnesis, ENT evaluation, and audiological evaluation were performed.

Gender, age, otologic complaints, presence of associated systemic diseases, and otoscopy findings were variables taken into account for the ENT assessment.

In the clinical assessment, the type, degree, and configuration of hearing loss observed in pure tone audiometry were considered, as well as the type of hearing aid worn. For the audiometry, an ITERA audiometer (Madsen, Denmark), calibrated in a soundproof booth according to the standards required by the Federal Council of Speech-Language Pathology, was used.

The subjects were divided into two groups for purposes of comparison and analysis of results: group A, made up of women, and group B, by men. The results were statistically analyzed using the chi-square test (to compare possible differences between observed and expected frequencies for an event) and the difference in proportions test (to compare differences between two populations), with 0.05 as the significance level.

\section{Results}

In the period that data were collected, 278 people presented for a follow-up visit at an accredited clinic. Of these, 61 (21\%) 
subjects reported otologic or operational problems with their devices.

The sample was composed of 61 individuals, 35 (57\%) women and 26 (43\%) men. The age in group A (women) ranged from 53 to 85 , with a mean of 72 , and in group $B$ (male), from 53 to 82 , with a mean of 69 . A family history of hearing loss was reported in $41 \%$ of subjects, 13 women and 12 men. There was a predominance of widows in group A (51\%), followed by married (37\%) and single (11\%), and group B was predominantly married (81\%), followed by divorced (11\%) and widowers (8\%). Both genders were mostly made up of retirees or pensioners ( $71 \%$ of the women and $85 \%$ of the men).

When talking about hearing aids, three individuals in group A used unilateral prosthesis, four used intracanal hearing aids, and 53 (86\%) used behind-the-ear (BTE) prosthesis with silicone molds. In the group $\mathrm{B}$, two individuals used prosthesis in one ear, six used intracanal hearing aids, and 48 (78\%) used BTE prosthesis with silicone molds.

Type, degree, and configuration of hearing loss are shown in - Table 1. The chi-square test predominantly showed mild to moderate hearing loss with descending slopes. About $80 \%$ of subjects had comorbidities, and the data are shown in -Table 2. Hypercholesterolemia was more significant for women and hypertension for males.

The majority of the sample (92\%) had bilateral fitting of hearing aids, with the same percentage represented in both groups. The hearing aid use profile is shown in - Table 3. Considering only the totals of continuous and discontinuous use, the chi-square test at a significance level of 0.05 showed no significant dependence between usage type between the two genders. Fourteen subjects (22\%) reported little use of hearing aids, either because of otologic problems associated with deafness or malfunction of the unit itself, and the results are shown in -Table 4 . Of the 61 participants, $54 \%$ had otologic complaints related to deafness, and the data are

Table 1 Classification of hearing loss and gender $(n=61)$

\begin{tabular}{|l|l|l|l|}
\hline \multirow{2}{*}{ Variable } & \multicolumn{2}{|c|}{ Gender } & \multirow{2}{*}{$p$} \\
\cline { 2 - 3 } & Women & Men & \\
\hline Type of loss & & & \\
\hline Sensorineural & 30 & 22 & 0.9047 \\
\hline Mixed & 5 & 4 & \\
\hline Degree of loss & & & \\
\hline Light & 3 & 7 & 0.0103 \\
\hline Moderate & 14 & 14 & \\
\hline Profound & 6 & - & \\
\hline Severe & 12 & 5 & \\
\hline Configuration & & & \\
\hline Descending & 18 & 20 & 0.0422 \\
\hline Flat & 17 & 6 & \\
\hline
\end{tabular}

Note: Using chi-square test, there is significant difference in the degree of loss $(p=0.0103)$ and configuration $(p=0.0422)$. presented in - Table 5; the correlation between morbidity and discontinuity of use for the hearing aid is shown in - Table 6.

\section{Discussion}

All 61 participants had hearing loss, and of these, 80.3\% reported having systemic diseases, among which the most commonly reported were hypertension, hypothyroidism, hypercholesterolemia, and diabetes. The study population had an average age of 69 years for men and 72 years for women; all were considered seniors. Although the appearance of systemic diseases and hearing loss is natural, it can often be disabling and contribute negatively to quality of life, generating increasing demands for specialized health care services.

To improve auditory perception, the elderly population has sought out hearing health services in SUS for evaluation of hearing and fitting of hearing aids. ${ }^{27,28}$ In the present study, conducted within a hearing health clinic, most of the sample was elderly.

A high incidence of morbidity was assessed in the sample, predominantly hypercholesterolemia in women and hypertension in men. Investments are necessary so that medical care for hearing health services is not restricted to ENT care. According to a published study, ${ }^{8}$ the body of an elderly person has peculiarities that must be evaluated when dealing with issues related to ENT disorders. The physician should consider underlying diseases, medical history, and the drugs taken by patients.

In the study group, $62 \%$ of women reported having no life partner; only $19 \%$ of men did not have a partner. This coincides with work that notes the feminization of old age associated with greater longevity and independence of women compared with men. ${ }^{11}$

There was a balance between the two genders with regard to occupation, as most were retired or pensioners. A study with 320 subjects in Curitiba revealed that more than half of the sample was made up of retirees and had a minimum wage income, which explains the use of the free, governmentsponsored SUS. $^{27}$

This study (-Table 1) was made up of patients with predominantly sensorineural hearing loss, from mild to moderate degree with a downward sloping audiometric curve, significant for both groups. As most subjects were elderly, the prevalence of hearing loss caused by aging (i.e., presbycusis) as found in other studies had been expected. ${ }^{12,20,29}$

The majority of the sample ( - Table 3 ) had been wearing a hearing aid for over 2 years, and 14 subjects (22\%) reported not using the device continuously, either because of otologic factors or functional factors with the device. There was no significant difference between the two genders regarding continuous or nonuse of the device. Studies point to the fact that it is common for users to give up on wearing hearing aids for several reasons, ranging from discomfort with the sound amplification to aesthetic considerations. ${ }^{28,29}$ In this study most respondents used BTE hearing aids. Of those who 
Table 2 Morbidities by gender $(n=61)$

\begin{tabular}{|l|l|l|l|l|}
\hline Comorbidities & Women $(\boldsymbol{n}=\mathbf{3 5})$ & Men $(\boldsymbol{n}=\mathbf{2 6 )}$ & Total $(\boldsymbol{n}=\mathbf{6 1 )}$ & $\boldsymbol{p}$ \\
\hline Hypercholesterolemia & $12(34.3 \%)$ & $3(11.5 \%)$ & $15(24.6 \%)$ & 0.0453 \\
\hline Diabetes & $8(22.9 \%)$ & $3(11.5 \%)$ & $11(18.0 \%)$ & 0.2568 \\
\hline Arterial hypertension & $26(74.3 \%)$ & $12(46.2 \%)$ & $38(62.3 \%)$ & 0.0289 \\
\hline Benign prostatic hyperplasia & - & $4(15.4 \%)$ & $4(6.6 \%)$ & N/A \\
\hline Rheumatic diseases & $2(5.7 \%)$ & - & $2(3.3 \%)$ & N/A \\
\hline Hypothyroidism & $13(37.1 \%)$ & $1(3.8 \%)$ & $423.0 \%)$ & N/A \\
\hline Psychiatric difficulties & $2(5.7 \%)$ & $2(7.7 \%)$ & $4.6 \%)$ & N/A \\
\hline Others & $2(5.7 \%)$ & $4(15.4 \%)$ & $6.8 \%)$ & N/A \\
\hline No mentioned morbidity & $4(11.4 \%)$ & $8(30.8 \%)$ & $12(19.7 \%)$ & 0.3187 \\
\hline
\end{tabular}

Abbreviation: N/A, not applicable.

Note: The number of citations is greater than the number of respondents because some individuals had more than one associated morbidity. Using the difference of proportions test, there is significant difference between the number of morbidities for hypercholesterolemia and hypertension.

Table 3 Time and method of use for the device $(n=61)$

\begin{tabular}{|l|l|l|l|l|}
\hline \multirow{2}{*}{ Time of use (mo) } & \multicolumn{2}{|c|}{ Women } & \multicolumn{2}{c|}{ Men } \\
\cline { 2 - 5 } & Continuous use & Discontinuous use & Continuous use & Discontinuous use \\
\hline$<12$ & 5 & - & 8 & 2 \\
\hline $13-24$ & 5 & 4 & 1 & 1 \\
\hline $25-36$ & 3 & 2 & 8 & 1 \\
\hline $37-48$ & 8 & - & - & 2 \\
\hline $49-96$ & 5 & 2 & 3 & - \\
\hline$\geq 97$ & 1 & - & - & - \\
\hline Total & 27 & 8 & 20 & 6 \\
\hline
\end{tabular}

Table 4 Motives for interruption of use for the device $(n=14)$

\begin{tabular}{|l|l|l|l|l|l|}
\hline \multirow{2}{*}{ Variable } & \multicolumn{5}{|c|}{ Motives } \\
\cline { 2 - 6 } & Otalgia & Itching & Noise & Device defect & Total \\
\hline Women & $1(7 \%)$ & $2(14 \%)$ & $3(21 \%)$ & $2(14 \%)$ & $8(57 \%)$ \\
\hline Men & $3(21 \%)$ & - & $1(7 \%)$ & $2(14 \%)$ & $6(43 \%)$ \\
\hline Total & $4(28 \%)$ & $2(14 \%)$ & $4(28 \%)$ & $4(28 \%)$ & $14(100 \%)$ \\
\hline
\end{tabular}

Table 5 Otologic complaints and improvement of symptoms with the use of hearing aids by gender $(n=33)$

\begin{tabular}{|c|c|c|c|c|c|c|}
\hline \multirow[t]{2}{*}{ Complaint } & \multicolumn{3}{|c|}{ Women } & \multicolumn{3}{|c|}{ Men } \\
\hline & $\begin{array}{l}\text { Number of } \\
\text { complaints }\end{array}$ & Improvement & \% Improvement & $\begin{array}{l}\text { Number of } \\
\text { complaints }\end{array}$ & Improvement & \% Improvement \\
\hline Wax & 18 & - & - & 18 & - & - \\
\hline Itching & 22 & - & - & 11 & - & - \\
\hline Dizziness & 10 & 2 & 20 & 7 & 2 & 29 \\
\hline Tinnitus & 30 & 16 & 53 & 18 & 10 & 56 \\
\hline Otalgia & 6 & - & - & 2 & - & - \\
\hline Other & - & - & - & 1 & - & - \\
\hline
\end{tabular}

Note: The number of complaints is greater than the number of respondents because some individuals had more than one complaint associated with hearing loss. Using the difference of proportions test, there was significant difference in the two genders for itching $(p=0.0085)$ and tinnitus $(p=0.0015)$. 
Table 6 Relationship between discontinuous use of the device with comorbidities $(n=61)$

\begin{tabular}{|l|l|l|}
\hline \multirow{2}{*}{ Comorbidities } & \multicolumn{2}{|l|}{ Discontinuous use } \\
\cline { 2 - 3 } & $\begin{array}{l}\text { Women } \\
(\boldsymbol{n}=\mathbf{8})\end{array}$ & $\begin{array}{l}\text { Men } \\
(\boldsymbol{n}=6)\end{array}$ \\
\hline Hypercholesterolemia & $4(11.4 \%)$ & $2(7.7 \%)$ \\
\hline Diabetes & $1(2.9 \%)$ & $2(7.7 \%)$ \\
\hline Arterial hypertension & $6(17.1 \%)$ & $3(11.5 \%)$ \\
\hline Benign prostatic hyperplasia & - & $2(7.7 \%)$ \\
\hline Hypothyroidism & $4(11.4 \%)$ & $1(3.8 \%)$ \\
\hline
\end{tabular}

Note: The number of citations is greater than the number of respondents because some individuals had more than one associated morbidity.

discontinued use of the device, half did so because of problems with the ear itself and half had problems with the device. Ear pain and itching may compromise the use of the device, because they prevent the adaptation of molds, ${ }^{28}$ and failures in the devices are among the most common causes of abandonment of use. ${ }^{27}$

Hearing loss is commonly accompanied by symptoms such as tinnitus, vertigo, and aural fullness. ${ }^{1}$ The most common otologic complaint in both groups was tinnitus, reported by 48 subjects, and the second most common was vertigo, reported by 17 subjects. Tinnitus is an otologic problem that manifests itself frequently in patients with hearing loss. ${ }^{19,20}$ This problem, besides compromising the proper use of the device, may reduce its benefits and cause significant emotional and psychiatric sequelae. Vertigo also compromises the user's adequate adaptation for the hearing aid. ${ }^{21}$

Contrary to the published literature ${ }^{18}$, tinnitus was significant among women in this study. ${ }^{18}$

Improvement in hearing symptoms was achieved, particularly for those complaining of tinnitus ( 16 women and 10 men), which confirms data from the literature. ${ }^{20,22}$ This information reinforces the thesis that the hearing aid constitutes an important resource for physicians and audiologists who engage in hearing rehabilitation.

After investigating the causes of otologic symptoms, systemic diseases should be studied as they may be generating their own complaints and cause discontinuation of hearing aid use because of the important relationship between hearing, metabolic, and vascular issues., ${ }^{3,13,15}$ In this study, 14 respondents who do not wear the device appropriately, referring to otologic problems such as tinnitus, vertigo, ear pain and itching, mentioned the presence of comorbidities (-Table 2).

The literature also reports that hypertension has been shown to be a common case in both genders, but in this study a predominance of males had this complaint. ${ }^{10,12}$

Finally, as reported in the literature, ${ }^{20,22}$ use of the hearing aid was decisive for reducing some complaints, such as decreased sensation of dizziness and tinnitus ( - Table 3 ) for both women and men.

\section{Conclusion}

This study showed that the incidence of systemic and otologic complaints is high in this population. During the data collection period, 278 people had follow-up visits; of these subjects, $61(21 \%)$ reported otologic problems or operational problems with their devices. Basocochlear hearing loss, a characteristic of presbycusis, was the most prevalent both in men and women, with the majority of the subjects studied being senior citizens. The most frequently reported comorbidities were hypercholesterolemia (more significant in women) and hypertension (more significant in men). In 14 subjects, use of the device had been discontinued and there was no significant difference between genders. The reasons for discontinuation of use were itching and tinnitus, with women complaining more often.

It is clear that this group of patients should be evaluated in its entirety, for actions of this nature can contribute to improving the quality of life and assisting in the process of hearing aid adaptation.

\section{References}

1 Zhan W, Cruickshanks KJ, Klein BEK, et al. Modifiable determinants of hearing impairment in adults. Prev Med 2011;53(4-5): 338-342

2 Hoffman HJ, Dobie RA, Ko CW, Themann CL, Murphy WJ. Americans hear as well or better today compared with 40 years ago: hearing threshold levels in the unscreened adult population of the United States, 1959-1962 and 1999-2004. Ear Hear 2010;31(6): 725-734

3 World Health Organization. Prevention of blindness and deafness. Available at: http://www.who.int/pbd/deafness/news/en/. Accessed November 9, 2012

4 Pierre PV, Fridberger A, Wikman A, Alexanderson K. Self-reported hearing difficulties, main income sources, and socio-economic status; a cross-sectional population-based study in Sweden. BMC Public Health 2012;12:874

5 Brasil. Ministério da saúde. Portaria no 587 de 7 de outubro de 2004, Anexo IV. 2004. Available at: http://dtr2001.saude.gov.br/ sas/PORTARIAS/Port2004/PT-587.htm. Accessed on July 14, 2014.

6 Shimidt MI, Duncan BB, Silva GA, et al. Chronic noncommunicable diseases in Brazil: burden and current challenges. Lancet 2011; 377(9781):1949-1961

7 Iwabashi JH, Jardim IS, Sizenando CS, Bento RF. Protocolo de seleção e adaptação de prótese auditiva para indivíduos adultos e idosos. Intl Arch Otorhinolaryngol 2011;15(2): 214-222

8 Miyaki MAM. Afecções otorrinolaringológicas no idoso: o impacto da polifarmácia. Revista do Hospital Universitário Pedro Ernesto 2012;11:83-91

9 Silveira MM, Pasqualotti A, Colussi EL. Prevalência de doenças crônicas e prática de atividades físicas em adultos e idosos. Rev Bras Promç Saúde 2012;25(2):209-214

10 Barros MBA, Francisco PMSB, Zanchetta LM, César CLG. Tendências das desigualdades sociais e demográficas na prevalência de doenças crônicas no Brasil, PNAD: 2003-2008. Cien Saude Colet 2011; 16(9):3755-3768

11 Souza EA, Scochi MJ, Maraschin MS. Estudo da morbidade em uma população idosa. Rev Esc Anna Nery 2011;15(2):380-388

12 Tenório JP, Guimarães JATL, Flores NGC, Iório MCM. Comparação entre critérios de classificação dos achados audiométricos em idosos. J Soc Bras Fonoaudiol 2011;23(2):114-118 
13 Mondelli MFCG, Lopes AC. Relação entre a hipertensão arterial e a deficiência auditiva. Intl Arch Otorhinolaryngol 2009;13(1):63-68

14 Turi BC, Codogno JS, Fernandes RA, Amaral SL, Monteiro HL. Frequência de ocorrência de doenças crônico-degenerativas em adultos com mais de 50 anos. Rev Bras Atv Fis Saúde 2010;15(4): 218-223

15 Malucelli DA, Malucelli FJ, Fonseca VR, et al. Hearing loss prevalence in patients with diabetes mellitus type 1 . Braz J Otorhinolaryngol 2012;78(3):105-115

16 Sousa CS, Castro Junior N, Larsson EJ, Cbing TH. Risk factors for presbycusis in a socioeconomic middleclass sample. Braz J Otorhinolaryngol 2009;75(4):530-536

17 Gibrin PCD, Melo JJ, Marchiori LLM. Prevalence of tinnitus complaints and probable association with hearing loss, diabetes mellitus and hypertension in elderly. CoDas 2013;25(2):176-180

18 Pinto PCL, Sanchez TG, Tomita S. The impact of gender, age and hearing loss on tinnitus severity. Braz J Otorhinolaryngol 2010; 76(1):18-24

19 Viacelli SNA, Costa-Ferreira MID. Perfil dos usuários de AASI com vistas à amplificação, cognição e processamento auditivo. Rev CEFAC 2013;15(5):1125-1136

20 Lacerda CF, Silva LO, Canto RST, Cheik NC. Efeitos da adaptação às próteses auditivas na qualidade de vida, no equilíbrio e no medo de queda em idosos com perda neurossensorial. Intl Arch Otorhinolaryngol 2012;16(2):156-162
21 Paulin F, Zeigelboim BS, Klagenberg KF, Rosa MRD. Achados vestibulares em usuários de aparelho de amplificação sonora individual. Rev CEFAC 2009;11(1):68-75

22 Munhoes dos Santos Ferrari G, Sanchez TG, Bovino Pedalini ME. The efficacy of open molds in controlling tinnitus. Braz J Otorhinolaryngol 2007;73(3):370-377

23 Silva RCF, Bandini HHM, Soares IA. Aparelho de amplificação sonora individual: melhora a sensação de zumbido? Rev CEFAC 2007;9(2):263-268

24 Word AP, Nezafati KA, Cruz PD Jr. Ear dermatitis + epoxy reactivity = hearing aid allergy? Dermatitis 2011;22(6):350-354

25 Sasseville D. Acrylates. Dermatitis 2012;23(1):3-5

26 Andersson G, Keshishi A, Baguley DM. Benefit from hearing aids in users with and without tinnitus. Audiol Med 2011;9(2):73-78

27 Ribas AR, Serratto MRF, Bento KA, Vieira M, Lourenço H, Costa TL. Perfil sócio-histórico de pacientes atendidos na clínica de fonoaudiologia da Universidade Tuiuti do Paraná. Rev Biociências. Biotecnologia e Saúde 2012;4(1):13-18

28 Rosa MRD, Dante G, Ribas A. Programa de orientação a usuários de prótese auditiva e questionários de autoavaliação: importantes instrumentos para uma adaptação auditiva efetiva. Intl Arch Otorhinolaryngol 2006;10(3):220-227

29 Ribeiro LM, Rasera EF. Os idosos e o uso de próteses auditivas: identificando os repertórios interpretativos que justificam essa decisão. Psicol Soc 2008;20(3):425-433 